\title{
Socio Demographic Profile and Risperidone Response in New Versus Old Schizophrenia Patients
}

\author{
Belbase $\mathrm{M}^{1}$, Adhikari J²
}

\section{ABSTRACT}

Introduction: Schizophrenia is a mental disorder characterized with disorganized thinking, perception, expression of reality with significant social and occupational dysfunction. Two groups of drugs are in recent use namely first generation (typicals) and second generation (atypical) antipsychotics. Risperidone is a broad spectrum antipsychotic and has a role as a first-line agent for first break, mild to moderately ill patients and for severely ill treatment-refractory patients. Aim: This article tries to compare the risperidone response in newly diagnosed schizophrenia patients versus old patients already on some antipsychotics other than risperidone. Methods: This is an experimental intervention study of patients attending to psychiatry OPD and indoor in Nepalgunj Medical College, Kohalpur. Total 40 patients ( 27 new and 13 old) were selected and sample was collected in one year from January 2018 till December 2018. Positive and negative syndrome scale questionnaire was used to record the positive and negative symptoms of schizophrenia on baseline (week 0). Patients were followed up on week 4 and week 8 and the same positive and negative syndrome scale questionnaire was applied to record the improvement. Risperidone was given in therapeutic dose (4-8mg) on the basis of symptoms and improvement. Results: The study subjects were divided into new $\mathrm{N}=27$ (17 male and 10 female) and old $\mathrm{N}=13$ (7 male and 6 female). Maximum number of schizophrenia cases were in age group 15-25 and 35-44 years comprising 30 $\%$ in each group. Mean total duration of illness in new group was $23.89 \pm 29.51$ months (median being 12.0 months) while in old group it was $123.69 \pm 83.34$ months (median being 96.0 months) with significant difference between two groups $(p=<0.001)$. The mean risperidone dose in milligram on base line (week 0 ) was $4.15 \pm 0.55$ for old group while it was $4.04 \pm 0.52$ for new group. On week 4 , the mean dose for old group was $5.08 \pm 0.95$ while for the new group it was $4.81 \pm 1.08$. On week 8 , the dose for old group was $6.08 \pm 1.32$ while it was $5.15 \pm 1.35$ for new group. There was a significant difference in the drug dose on week 8 between old group and new group with $p$ value of $\mathbf{0 . 0 4 7}$ (statistically significant). Conclusion: Our study suggests that schizophrenia is found in most productive age group. Risperidone is effective in both new and old schizophrenia patients however old patients need higher dose of risperidone than new patients.

\section{Keywords: Atypicals, Risperidone, Schizophrenia, Typicals}

1. Dr. Mohan Belbase

2. Dr. Jyoti Adhikari

${ }^{1}$ Department of Psychiatry, Nepalgunj Medical College and Teaching Hospital, Kohalpur, Banke

${ }^{2}$ Department of Pediatrics, Nepalgunj Medical College and Teaching Hospital, Kohalpur, Banke

\section{Address for Correspondence:}

\author{
Dr. Mohan Belbase \\ Associate Professor \\ Department of Psychiatry \\ Nepalgunj Medical College and Teaching Hospital \\ Kohalpur, Banke, Nepal \\ Email: mohanbelbase90@gmail.com
}

\section{INTRODUCTION}

Schizophrenia is a mental disorder characterized with disorganized thinking, perception, expression of reality with significant social and occupational dysfunction. The term coined by Eugen Bleuler to denote splitting of psychic functions. ${ }^{1}$ It afflicts $1 \%$ of population, usually begins before age 25 and persists throughout life. It inflicts persons of all social classes and comprises a group of disorders with heterogeneous causes and outcome. ${ }^{2}$
Two groups of drugs are in recent use namely first generation (typical) and second generation antipsychotics (atypical). First generation like haloperidol are said to cause more adverse effects including extrapyramidal side effects but second generations including risperidone causes other side effects including metabolic syndrome. There are case reports of deaths due to diabetic ketoacidosis in atypical antipsychotic users. ${ }^{3}$ Though there is no clear evidence of difference in effectiveness between two groups of drugs, first generation are said to be effective in positive symptoms while second generations are effective in both positive as well as negative symptoms of 
schizophrenia. More than ninety percent of patients are now treated using second generation drugs. Risperidone is a broad spectrum antipsychotic and has a role as a first-line agent for first break, mild to moderately ill patients and for severely ill treatment-refractory patients. ${ }^{2}$ Though not many such type of studies from Nepal, one study showed risperidone to have quicker and better action than haloperidol with better safety profile in Nepali Schizophrenia patients. ${ }^{4}$ Another similar study from India shows risperidone to have an edge over haloperidol in some of the psychosocial areas and overall clinical improvement. ${ }^{5}$

This article tries to compare the risperidone response in newly diagnosed schizophrenia patients versus old patients already on some antipsychotics other than risperidone.

\section{METHODS}

This is an experimental intervention study of patients attending to psychiatry OPD and indoor in Nepalgunj Medical College, Kohalpur. Diagnosis of schizophrenia was made based on ICD10 criteria for research. The diagnosed cases were subdivided into new and old schizophrenia patients. These patients were examined and their symptoms were recorded by using modified positive and negative syndrome scale questionnaire on baseline (week zero), week four and week eight. Risperidone was given in the therapeutic dose as per needed in every visit. Biochemical and radiological investigations was done as required. After a written consent from patient or primary caretaker, patients aged 15-65 of either sex were included in the study. Patients having gross organic brain disorders, dependent on any kind of psychoactive substance, mental retardation were excluded from the study. A semi-structured performa was used to record the basic socio-demographic details.

Total 40 patients ( 27 new and 13 old) were selected and sample was collected in one year from January 2018 till December 2018. PANNS questionnaire was used to record the positive and negative symptoms of schizophrenia on baseline (week 0 ). Patients were followed up on week 4 and week 8 and the same PANNS (positive and negative syndrome scale) questionnaire was applied to record the improvement. Risperidone was given in therapeutic dose (4-8mg) on the basis of symptoms and improvement. These PANNS scores were compared and analyzed. Recorded data were assessed using SPSS using parametric (students t-test) and non parametric technique (Mann Whitney $U$ test). Ethical consideration was done by obtaining the informed written consent from the subject or immediate guardian. Strict confidentiality of the information was maintained and result was utilized for the appropriate management of the cases concerned, similar cases in general and research purpose.
Instruments used in the study were

1. The ICD- 10 classification of mental and behavioral disorders, diagnostic criteria for research for schizophrenia

2. Semi structured performa developed by department

3. PANNS (positive and negative syndrome scale, modified)

\section{RESULTS}

The study subjects were divided into new $\mathrm{N}=27$ (17 male and 10 female) and old $\mathrm{N}=13$ (7 male and 6 female). Results are tabulated below.

Among the significant findings, mean total duration of illness in new group was $23.89 \pm 29.51$ months (median being 12.0 months) while in old group it was $123.69 \pm 83.34$ months (median being 96.0 months) with significant difference between two groups $(p=<0.001)$.

The mean risperidone dose in milligram on base line (week 0) was $4.15 \pm 0.55$ for old group while it was $4.04 \pm 0.52$ for new group. On week 4 , the mean dose for old group was $5.08 \pm$ 0.95 while for the new group it was $4.81 \pm 1.08$. On week 8 , the dose for old group was $6.08 \pm 1.32$ while it was $5.15 \pm 1.35$ for new group. There was a significant difference in the drug dose on week 8 between old group and new group with $p$ value of $\mathbf{0 . 0 4 7}$ (statistically significant).

There was no significant difference in the PANNS scores on base line, on $4^{\text {th }}$ week and $8^{\text {th }}$ week when comparing between the new old group using Mann Whitney $U$ test $(p=<0.05)$ suggesting that risperidone was equally effective in new as well as old schizophrenia patients.

\begin{tabular}{|c|c|c|c|}
\hline Characteristics & Categories & $\begin{array}{l}\text { Frequency } \\
(n)=40\end{array}$ & Percentage (\%) \\
\hline \multirow{5}{*}{ Age in years } & $15-24$ & 12 & 30 \\
\hline & $25-34$ & 10 & 25 \\
\hline & $35-44$ & 12 & 30 \\
\hline & $45-54$ & 4 & 10 \\
\hline & $55-64$ & 2 & 5 \\
\hline \multirow{2}{*}{ Gender } & Male & 24 & 60 \\
\hline & Female & 16 & 40 \\
\hline \multirow{2}{*}{ Marital status } & Married & 28 & 70 \\
\hline & Unmarried & 12 & 30 \\
\hline \multirow{2}{*}{ Religion } & Hindu & 35 & 87.5 \\
\hline & Muslim & 5 & 12.5 \\
\hline \multirow{3}{*}{ Education } & Illiterate & 10 & 25 \\
\hline & Literate & 29 & 72.5 \\
\hline & Higher education & 1 & 2.5 \\
\hline \multirow{6}{*}{ Occupation } & Farmer & 8 & 20 \\
\hline & Service & 3 & 7.5 \\
\hline & Student & 4 & 10 \\
\hline & Housewife & 13 & 32.5 \\
\hline & Teacher & 1 & 2.5 \\
\hline & Unemployed & 11 & 27.5 \\
\hline \multirow{2}{*}{$\begin{array}{l}\text { Socioeconomic } \\
\text { status }\end{array}$} & Lower & 18 & 45 \\
\hline & Lower-middle & 22 & 55 \\
\hline \multirow{2}{*}{ Family type } & Nuclear & 7 & 17.5 \\
\hline & Joint & 33 & 82.5 \\
\hline
\end{tabular}


Belbase et al.: Socio Demographic Profile and Risperidone Response in New Versus Old Schizophrenia Patients

\begin{tabular}{|c|c|c|c|c|c|}
\hline \multirow{2}{*}{ Characteristics } & \multirow{2}{*}{ Categories } & \multicolumn{2}{|c|}{ Treatment group } & \multirow{2}{*}{ P-value* } & \multirow{2}{*}{ Remarks } \\
\hline & & New & Old & & \\
\hline \multirow{2}{*}{ Sex } & Male & 17 & 7 & \multirow{2}{*}{0.836} & \multirow{2}{*}{ NS } \\
\hline & Female & 10 & 6 & & \\
\hline \multirow{2}{*}{ Marital status } & Married & 18 & 10 & \multirow{2}{*}{0.391} & \multirow{2}{*}{ NS } \\
\hline & Unmarried & 9 & 3 & & \\
\hline \multirow{2}{*}{ Religion } & Hindu & 23 & 12 & \multirow{2}{*}{0.469} & \multirow{2}{*}{ NS } \\
\hline & Muslim & 4 & 1 & & \\
\hline \multirow{2}{*}{ Education level } & Illiterate & 8 & 2 & \multirow{2}{*}{0.286} & \multirow{2}{*}{ NS } \\
\hline & Literate & 19 & 11 & & \\
\hline \multirow{2}{*}{ Occupation } & Job holders & 1 & 3 & \multirow{2}{*}{0.092} & \multirow{2}{*}{ NS } \\
\hline & Others & 26 & 10 & & \\
\hline \multirow{2}{*}{$\begin{array}{l}\text { Socio-economic } \\
\text { status }\end{array}$} & Lower & 12 & 6 & \multirow{2}{*}{0.592} & \multirow{2}{*}{ NS } \\
\hline & $\begin{array}{l}\text { Lower- } \\
\text { middle }\end{array}$ & 15 & 7 & & \\
\hline \multirow{2}{*}{ Family type } & Nuclear & 4 & 3 & \multirow{2}{*}{0.408} & \multirow{2}{*}{ NS } \\
\hline & Joint & 23 & 10 & & \\
\hline
\end{tabular}

*t-test

Table II : Association between treatment groups (new and old schizophrenia patients) and socio-demographic profile of patients

\begin{tabular}{|c|c|c|c|c|c|}
\hline \multicolumn{2}{|c|}{ Mean risperidone dose } & \multirow{2}{*}{$\begin{array}{c}\text { Exposed } \\
4.15\end{array}$} & \multirow{2}{*}{$\begin{array}{c}\text { St. Deviation } \\
0.55\end{array}$} & \multirow{3}{*}{$\begin{array}{c}\text { P. value* } \\
0.517\end{array}$} & \multirow{3}{*}{$\begin{array}{c}\text { Remarks } \\
\text { NS }\end{array}$} \\
\hline \multirow{2}{*}{$\begin{array}{l}\text { Risperidone } 0 \\
\text { (baseline) }\end{array}$} & Old & & & & \\
\hline & New & 4.04 & 0.52 & & \\
\hline \multirow{2}{*}{$\begin{array}{l}\text { Risperidone } 4 \\
\quad\left(4^{\text {th }} \text { week }\right)\end{array}$} & Old & 5.08 & 0.95 & \multirow{2}{*}{0.459} & \multirow{2}{*}{ NS } \\
\hline & New & 4.81 & 1.08 & & \\
\hline \multirow{2}{*}{$\begin{array}{c}\text { Risperidone } 8 \\
\left(8^{\text {th }} \text { week }\right)\end{array}$} & Old & 6.08 & 1.32 & \multirow{2}{*}{0.047} & \multirow{2}{*}{$\mathbf{S}$} \\
\hline & New & 5.15 & 1.35 & & \\
\hline
\end{tabular}

*t-test-Sig(2-tailed)

Table III : Relationship between mean risperidone doses and PANSS scores over follow ups

\begin{tabular}{|ccccccc|}
\hline Scores & Groups & Median & $\begin{array}{c}\mathbf{1}^{\text {st }} \\
\text { quartile }\end{array}$ & $\begin{array}{c}\mathbf{3}^{\text {rd }} \\
\text { quartile }\end{array}$ & $\begin{array}{c}\text { P } \\
\text { value* }\end{array}$ & Remarks \\
\hline \multirow{2}{*}{ Age } & Old & 34.0 & 21.5 & 41.0 & & \\
& New & 30.0 & 24.0 & 40.0 & 0.909 & NS \\
& Total & 31.5 & 22.5 & 40.0 & & \\
\hline Duration & Old & 96.0 & 66.0 & 168.0 & & \\
of illness & New & 12.0 & 3.0 & 36.0 & $<0.001$ & S \\
(months) & Total & 30.0 & 7.25 & 72.09 & & \\
& Old & 53.00 & 45.00 & 56.00 & 0.711 & NS \\
\hline \multirow{2}{*}{ PANSS 0 } & New & 52.00 & 40.00 & 64.00 & & \\
& Total & 53.00 & 42.00 & 61.75 & & \\
& Old & 28.00 & 27.50 & 34.00 & \multirow{2}{*}{0.549} & NS \\
\hline \multirow{2}{*}{ PANSS 4 } & New & 25.00 & 21.00 & 36.00 & & \\
& Total & 28.00 & 22.25 & 35.75 & & \\
\hline & Old & 16.00 & 12.50 & 21.00 & 0.252 & NS \\
\hline \multirow{2}{*}{ PANSS 8 } & New & 14.00 & 8.00 & 19.00 & & \\
& Total & 14.00 & 9.50 & 19.75 & & \\
\hline
\end{tabular}

*Mann Whitney U test

Table IV : Table showing age, duration of illness and comparisons of PANNS scores on baseline (week 0), week 4 and week 8 between new and old schizophrenia group with their significance.

\section{DISCUSSION}

Maximum number of schizophrenia cases were in age group 15-24 and 35-44 years comprising $30 \%$ in each group. This is similar to an Indian study in which the median age of schizophrenia was 28.5 years. ${ }^{6}$

Most of the patients were male (60\%) and married (70\%). Schizophrenia is equally common in male and female, this finding may be due to male being brought to health care facility sooner and more often due to male dominance in society and male being bread winner of family. Schizophrenia patients usually remain unmarried but the opposite finding in our study could be belief system in our society where marriage is regarded as treatment for many mental problems.

Most of the patients were Hindu (87.5\%) while others were Muslims (12.5\%) which is in accordance to population distribution of mid-western Nepal. Most of our patients were from joint family covering $82.5 \%$ while $17.5 \%$ were from nuclear family. This is bit unusual in comparison to western literature where schizophrenia patients mostly live alone. This could be due to our culture of joint family.

Numerous studies have examined the comparative effectiveness and tolerability of various antipsychotics and in general they appear to be similarly effective with substantial difference in their adverse effects except for clozapine. Amisulpride, olanzapine, and risperidone have been shown in some meta-analyses to produce greater symptom response than antipsychotics other than clozapine. ${ }^{7}$

Some literature also mention about better risperidone response in newly diagnosed patients without previous exposure to any neuroleptics. This study suggests significant difference in the dose of risperidone on week 8 between new and old schizophrenia patients with $\mathrm{P}=0.047(<0.05)$. This indicates old patients need higher dose of risperidone than new patients. One study regarding comparing of risperidone and haloperidole in first episode psychosis, $42 \%$ of the risperidone group experienced a relapse compared with $55 \%$ of haloperidole group. The median time for relapse was 466 days for risperidone treated subjects while 205 days for haloperidole received group. It concluded that long term risperidone prevents relapse in more patients and for longer time. ${ }^{8}$

In another study regarding maintenance treatment of schizophrenia with risperidone or haloperidole: 2 year outcome, when compared with patients given a low doses of haloperidole, risperidone treated patient experienced similar improvement in positive and negative symptoms and similar risk of psychotic exacerbations. However risperidone treated patients appeared to fell subjectively better, as indicated by less anxiety and depression with fewer extrapyramidal side effects as compared to haloperidole. ${ }^{9}$ 
Another study in Nepali schizophrenia patients reveals risperidone to have quicker and better action than haloperidol with better safety profile. ${ }^{4}$

This study suggests risperidone to be effective in new and old schizophrenia patients.

\section{LIMITATION}

Small sample size, unable to randomize the sample, short duration of follow ups, unequal size of sample in two groups and non-blind study without placebo control are some of limitations of this study.

\section{CONCLUSION}

Our study suggests that schizophrenia is found in most productive age group. Risperidone is effective in both new and old schizophrenia patients however old patients need higher dose of risperidone than new patients.

\section{REFERENCES}

1. Hemilton M, Fish's clinical psychopatholgy sign and symptoms in psychiatry. $2^{\text {nd }}$ ed. England: John wright \& sons;1985.

2. Sadock BJ, Sadok VA, synopsis of psychiatry behavioral science/ clinical psychiatry. $10^{\text {th }}$ ed. Philadelphia: Lippincott Williams \& Wilkins; 2007.

3. Thapa P B. The U. S. Clinical antipsychotic trails of intervention effectiveness (CATIE) study lessons for treatment of chronic schizophrenics. Souviner $2^{\text {nd }}$ international conference of SAARC psychiatric federation 2007

4. Tamrakar SM, Nepal MK, Koirala NR, et al. Journal of Nepal Medical Association, 2005 Jan-Feb; 44:46.

5. Shrivastava A, Sarkhel G. Comparative study of risperidone and haloperidol on clinical and psychosocial parameters in treatment of schizophrenia: a randomized open trail. Indian Journal of Psychiatry 2000;42 (1):52-56.

6. Agashe M, Dhawale DM, Cozma $G$ et al. Risperidone in schizophrenia. Indian Journal of Psychiaty 1999; 41(1):54-59.

7. Sadock BJ, Sadock VA, Ruiz P. Comprehensive textbook of psychiatry. $10^{\text {th }}$ ed. Philadelphia: Wolters Kluwer; 2017. p. 1523.

8. Schooler Nina, Rabinowitz Jonathan, davidsons Michael et al. Risperidone and haloperidole in first episode psychosis: A long term randomized trail, American J psychiatry 2005; 162:947953.

9. Marder R, Glynn M, Wirshing C et al. Maintenance treatment of schizophrenia with risperidone or haloperidole: 2-year outcomes. Americal J Psychiatry 2003; 160:1405-1412. 